\title{
ANÁLISES DE INCLUSÕES NO AÇO INOXIDÁVEL FERRÍTICO 409*
}

\section{Resumo}

\author{
Márcio Nascimento Cunha ${ }^{1}$ \\ Valdeci Paula Alvarenga ${ }^{2}$ \\ Hélio José Batista Alves ${ }^{3}$ \\ Dagoberto Brandão Santos ${ }^{4}$
}

O aço inoxidável ferrítico 409 é um aço suscetível a grande quantidade de inclusões. Determinar a origem das inclusões não é uma tarefa fácil e o conhecimento dos processos que fazem parte das etapas de produção do aço aliados a um bom método de caracterização são pontos importantes na identificação da origem das inclusões e solução de problemas de qualidade. A proposta deste é trabalho caracterizar inclusões no aço AISI 409 em todas as etapas de produção na Aciaria utilizando técnicas de microscopia e análise química. Amostras do aço líquido e escória foram retiradas em cada etapa de produção. Análises de composição química do aço e escória foram realizadas através de espectrometria de energia dispersiva de raios $X$ (EDS). As inclusões no aço foram examinadas através de um microscópio óptico com analisador de imagem, quantificadas e caracterizadas em termos de composição química no MEV-EDS. Os resultados mostraram que a composição química das inclusões modifica de acordo com o tratamento em cada etapa de processo e a condição de limpidez da corrida é afetada após adições de Ti no Forno Panela e no distribuidor do lingotamento contínuo.

Palavras-chave: Aço inoxidável AISI 409; Inclusões; Óxidos; Processos.

\section{INCLUSIONS ANALYSISINFERRITIC STAINLESS STEEL TYPE 409}

\begin{abstract}
Ferritic stainless steel 409 is sensible to a large amount of inclusions. To determine the origin of inclusions is not an easy work. Knowledge about the production process and a good characterization method of inclusions are important points on the identification and how to solve quality problems. This work has the objective to characterizer inclusion on the AISI 409 stainless steel grade in all production steps on the melt shop by microscopy method and microprobe. Samples of the melt steel and slag were obtained in each step of production. Chemical composition of steel and slag were checked by x-ray energy dispersive spectrometry (EDS). The inclusions were analyzed by optical microscopy, and SEM-EDS. Results showed the chemical composition is modified according to the treatment in each process and the cleanness is effected after Ti addition at Ladle Furnace and at tundish during the continuous casting.
\end{abstract}

Keywords: Stainless steel type AISI 409; Inclusions, Oxide; Process.

1 Engenheiro de Materiais, Engenheiro Metalurgista do produto inox, Aperam South America, Timóteo, Minas Gerais, Brasil.

2 Mestre em Engenharia Metalúrgica, Pesquisador do produto inox, Aperam South America, Timóteo, Minas Gerais, Brasil.

3 Mestre em Engenharia Metalúrgica, Engenheiro Metalurgista de processo, Aperam South America, Timóteo, Minas Gerais, Brasil.

4 Doutor em Engenharia Metalúrgica, Professor do departamento de Engenharia Metalúrgica e de Materiais da UFMG, Belo Horizonte, Minas Gerais, Brasil. 


\section{INTRODUÇÃO}

O aço inoxidável ferrítico AISI 409 tem grande aplicação na indústria automobilística nos sistemas de exaustão de automóveis, apresenta teor de cromo de $11 \%$, somatório $(\mathrm{C}+\mathrm{N})$ menor que 200ppm e aproximadamente $0,16 \%$ de titânio. A presença de titânio na composição química e a afinidade deste elemento pelo nitrogênio e oxigênio tornam o aço susceptível a uma grande quantidade de inclusões devido à possibilidade de formação de nitretos e óxidos. Estas inclusões passam para o molde através da válvula submersa e geram grande quantidade de defeitos após laminação e em casos mais graves causam obstrução da válvula submersa com interrupção do lingotamento.

Análises de caracterização do defeito são realizadas com frequência e sempre mostram a presença de inclusões, porém a dificuldade está sempre na determinação do local de origem destas inclusões.

Durante o processo de fabricação dos aços, diversas reações químicas ocorrem e como resultado destas reações, as inclusões são formadas. Desta forma, inclusões são uma consequência inevitável do processo e podem se formar devido às operações de desoxidação, tratamentos inadequados, desgastes de refratários, reoxidação do aço líquido pelo ar ou escória, arraste mecânico de escória da panela e do distribuidor ou incrustação de pófluxante no molde [1].

A determinação das origens e natureza das inclusões não é uma tarefa fácil. As inclusões possuem origens e natureza amplamente diferentes. Conhecer as etapas do processo de fabricação do aço é um passo importante para se conhecer as possíveis fontes de inclusões [1].

Os aços inoxidáveis, assim como os demais tipos de aços, contêm inclusões. Inclusões não metálicas é a principal causa de defeitos superficiais originados na Aciaria, denominados "esfoliações", que são inclusões que afloram à superfície da chapa após laminação. Como o apelo estético é requerido para aplicações dos aços inoxidáveis, defeitos como esfoliações geram sucata do produto final [2].

O presente trabalho tem o objetivo de caracterizar inclusões formadas no aço 409 em todas as etapas de produção na Aciaria e avaliar como estas inclusões ocorrem durante a elaboração do aço, em quais etapas do processo aparecem em maior quantidade e se sofrem alterações ao longo desse processamento.

\section{MATERIAL E MÉTODOS}

\subsection{Amostragem}

A evolução da formação de inclusões no aço inoxidável 409 foi realizada mediante acompanhamento e amostragens durante a produção de uma corrida padrão na siderúrgica APERAM localizada na cidade de Timóteo-MG.

Foi realizada amostragem do aço líquido e escória em etapas específicas do processo na Aciaria. Foram retiradas duas amostras do aço líquido (uma para análise química e outra para análise de inclusões). O método de amostragem, assim como o tipo da amostra, foi o mesmo adotado pela empresa para realização das análises químicas durante a produção. Neste procedimento, a amostra do aço líquido é solidificada no formato de um medalhão, como é conhecido na indústria [1]. As tabelas 1 e 2 apresentam o esquema de amostragem do aço e escória. Foram obtidas 06 amostras do aço e 05 amostras de escória. 
Tabela 1. Esquema de amostragem do aço na Aciaria.

\begin{tabular}{|l|l|l|}
\hline Amostra & \multicolumn{1}{|c|}{ Etapa do processo } & \multicolumn{1}{c|}{ Momento de amostragem } \\
\hline A1 & AOD & Após vazamento do aço na panela. \\
\hline A2 & VOD & Após estapa de sopro. \\
\hline A3 & VOD & Após etapa de redução. \\
\hline A4 & Forno Panela & 5 minutos de flotação após adição de titânio. \\
\hline A5 & Forno Panela & 8 minutos de flotação após adição de titânio. \\
\hline A6 & Distribuidor Lingotamento & 20 minutos de lingotamento. \\
\hline
\end{tabular}

Tabela 2. Esquema de amostragem da escória na Aciaria.

\begin{tabular}{|l|l|l|}
\hline Amostra & \multicolumn{1}{|c|}{ Etapa do processo } & \multicolumn{1}{c|}{ Momento de amostragem } \\
\hline E1 & AOD & Após etapa de redução. \\
\hline E2 & VOD & Após etapa de redução. \\
\hline E3 & Forno Panela & Antes da adição de titânio. \\
\hline E4 & Forno Panela & 5 minutos de flotação após adição de titânio. \\
\hline E5 & Forno Panela & 8 minutos de flotacão após adição de titânio. \\
\hline
\end{tabular}

\subsection{Preparação das Amostras}

Amostras para análise microscópica foram preparadas no laboratório do Centro de Pesquisas da APERAM, seguindo as etapas de corte, embutimento, lixamento e polimento metalográfico.

Como a amostra apresenta tendência de formação de defeitos de solidificação no centro (vazios), e para evitar que estes defeitos fossem confundidos com inclusões, a superfície a ser analisada foi definida como uma superfície distante da região central da amostra. A seção a ser analisada foi uma área de $10 \times 15 \mathrm{~mm}$ como mostra a figura 1.

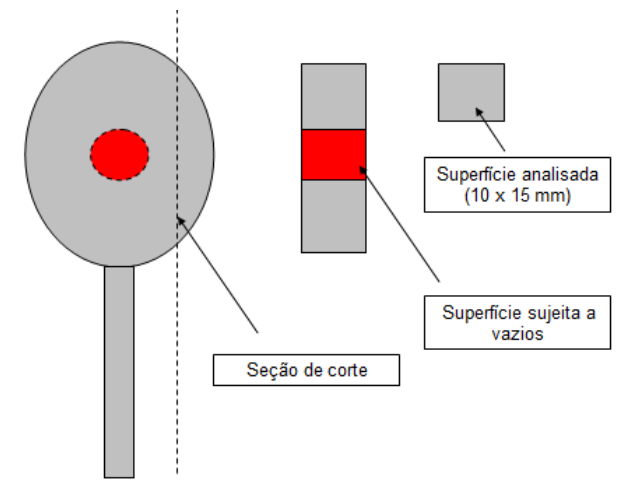

Figura 1. Padrao detınıdo para preparaçao da supertıcıe a ser analisada.

\subsection{Análises}

Análises de composição química no aço e escória foram realizadas no Laboratório Químico da APERAM. Exames e análises de microscopia óptica e eletrônica foram realizados no Centro de Pesquisas da APERAM. Foram utilizados aumentos 500X, buscando a área com maior quantidade de inclusões (pior área da amostra).

A análise de composição química das inclusões foi realizada com sistema EDS, acoplado a um Microscópio Eletrônico de Varredura (MEV). Além da composição química, foi avaliado a quantidade e tamanho das inclusões por campos nas áreas definidas. A pior área da amostra foi dividida em 50 campos e todas as inclusões nestes campos foram analisadas. Foi considerado os resultados de análises química somente das inclusões com tamanho $\geq 2 \mu \mathrm{m}$. 


\section{RESULTADOS E DISCUSSÃO}

\subsection{Composição Química do Aço e Escória}

As tabelas 3 e 4 apresentam os resultados de composição do aço e escória em cada fase do processo.

Tabela 3. Resultados de composição do aço.

\begin{tabular}{|l|c|c|c|c|c|c|c|c|c|c|c|}
\hline Amostra & $\mathbf{C}(\%)$ & $\mathbf{M n}(\%)$ & $\mathbf{S i}(\%)$ & $\mathbf{S}(\%)$ & $\mathbf{C r}(\%)$ & $\mathbf{T i}(\%)$ & $\mathbf{N b}(\%)$ & Al (\%) & $\mathbf{C a}(\%)$ & $\mathbf{N}(\%)$ & $\mathbf{O}(\%)$ \\
\hline A1 & 0,39 & 0,2 & 0,03 & 0,0067 & 11,15 & 0,004 & 0,055 & 0,0014 & 0,0004 & 0,01 & 0,0037 \\
\hline A2 & 0,0021 & 0,14 & 0 & 0,0037 & 10,38 & 0,0021 & 0,0063 & 0,001 & 0,0004 & 0,0054 & 0,04 \\
\hline A3 & 0,0046 & 0,2 & 0,44 & 0,0005 & 10,97 & 0,0044 & 0,035 & 0,0016 & 0,0005 & 0,0052 & 0,0026 \\
\hline A4 & 0,0063 & 0,2 & 0,5 & 0,0004 & 10,89 & 0,2 & 0,04 & 0,0036 & 0,0007 & 0,0061 & 0,0034 \\
\hline A5 & 0,0062 & 0,2 & 0,51 & 0,0007 & 10,85 & 0,19 & 0,036 & 0,0037 & 0,0008 & 0,0061 & 0,0035 \\
\hline A6 & 0,0059 & 0,2 & 0,51 & 0,0004 & 10,86 & 0,19 & 0,037 & 0,0036 & 0,0006 & 0,0057 & 0,0026 \\
\hline
\end{tabular}

Tabela 4. Resultados de composição da escória.

\begin{tabular}{|l|c|c|c|c|c|c|c|c|}
\hline Amostra & $\mathrm{CaO}(\%)$ & $\mathrm{SiO}_{2}(\%)$ & $\mathrm{MnO}(\%)$ & $\mathrm{MgO}(\%)$ & $\mathrm{Al}_{2} \mathbf{O}_{3}(\%)$ & $\mathrm{Cr}_{2} \mathbf{O}_{3}(\%)$ & $\mathrm{TiO}_{2}(\%)$ & $\mathrm{FeO}(\%)$ \\
\hline E1 & 54,51 & 29,66 & 0 & 9,29 & 2,25 & 0,39 & 0,55 & 0,71 \\
\hline E2 & 58,48 & 30,38 & 0 & 7,81 & 0,89 & 0,37 & 0,21 & 0,43 \\
\hline E3 & 57,47 & 31,18 & 0 & 8,31 & 0,93 & 0,36 & 0,26 & 0,19 \\
\hline E4 & 57,64 & 29,17 & 0 & 8,18 & 1,02 & 0,18 & 2,42 & 0,08 \\
\hline E5 & 57,38 & 29,14 & 0 & 8,06 & 1,03 & 0,17 & 2,55 & 0,1 \\
\hline
\end{tabular}

\subsection{Exameno Microscópio Óptico}

A figura 2 apresenta as características das amostras examinadas no microscópio óptico com aumento de 500X em cada etapa da elaboração do aço 409.
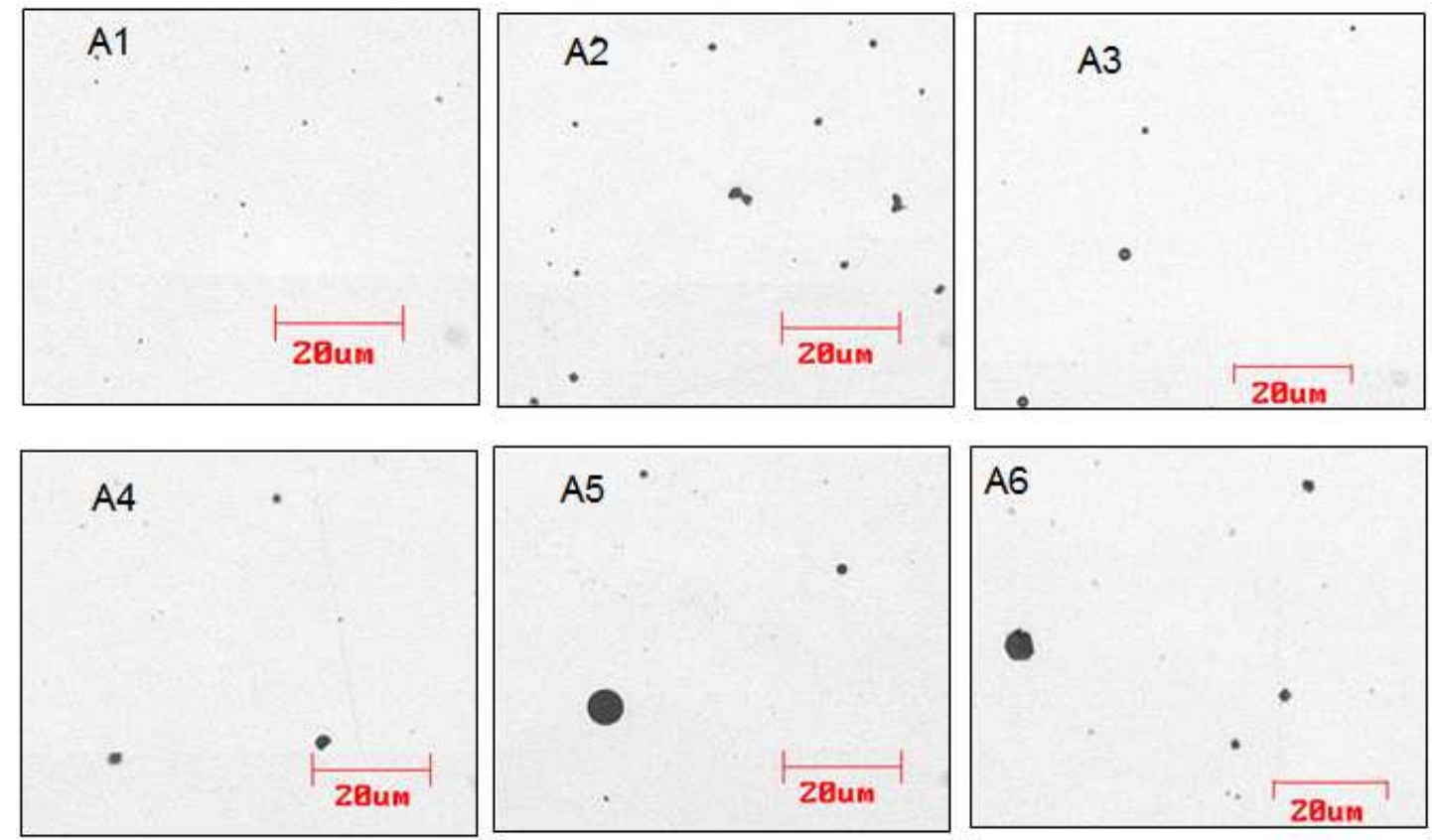

Figura 2. Resultados dos exames no microscópio óptico. Amostras A1, A2, A3, A4, A5 e A6 conforme esquema de amostragem.

Após processo do AOD (amostra A1), pequenas inclusões são observadas com boa condição de limpidez da corrida. Nesta etapa do processo, o nível de oxidação da 
corrida não é tão acentuado, visto que não é a finalidade de o processo obter níveis de carbono muito baixos. O volume de oxigênio fornecido não é suficiente para oxidar grande quantidade de metais no banho tornando mais fácil o processo e desoxidação da corrida.

Após sopro no VOD, grandes quantidades de inclusões aparecem na amostra A2. Embora não sejam inclusões grandes, esta observação reforça a necessidade de um bom controle nas etapas seguintes do processo para garantir que estas inclusões não permaneçam no aço.

Após o processo de redução no VOD (amostra A3), a quantidade de inclusões observadas é reduzida drasticamente conferindo a corrida uma boa condição de limpidez. A adição de FeSi recupera o cromo oxidado após sopro e também realiza a desoxidação. A etapa de homogeneização sob vácuo favorece a remoção das inclusões formadas como produto da desoxidação.

No forno panela é realizada a adição de titânio nas etapas finais de refino do aço. $O$ titânio é um elemento que se oxida facilmente. Após a adição de titânio, a flotação é realizada no sentido de remover através da escória os óxidos formados nesta etapa. Exame na amostra A4 mostra que com 5 min de flotação, a corrida apresenta um bom nível de limpidez com muitas inclusões, porém pequenas.

Com 8 min de flotação (amostra A5), a boa limpidez da corrida é mantida, no entanto, é observado inclusões um pouco maiores e mais arredondadas. Comprovando que o tempo de flotação favorece o crescimento das inclusões. A amostra A6, retirada do distribuidor mostra uma condição pior com uma quantidade maior de inclusões e de formato mais irregular do que as observadas anteriormente. No microscópio é possível observar ao fundo partículas muito pequenas com coloração amareladas característica do TiN indicando a possibilidade de precipitação deste nitreto.

\subsection{Análise Quantitativa no MEV}

A tabela 5 apresenta os resultados quantitativos obtidos na análise de partículas por campo no MEV.

Tabela 5. Resultados quantitativos das inclusões no MEV.

\begin{tabular}{|c|c|c|c|}
\hline Amostra & Total de inclusões no campo & Total de inclusões maior ou igual a 2 $\boldsymbol{\mu m}$ & Tamanho máximo $(\boldsymbol{\mu m})$ \\
\hline A1 & 207 & 10 & 5 \\
\hline A2 & 496 & 139 & 7 \\
\hline A3 & 286 & 7 & 5 \\
\hline A4 & 463 & 8 & 4 \\
\hline A5 & 406 & 10 & 5 \\
\hline A6 & 422 & 80 & 5 \\
\hline
\end{tabular}

Os resultados apresentaram bem coerentes com as observações realizadas no exame por microscópico óptico. Menores quantidades de inclusões foram observadas nas amostras A1 (após AOD com nível menor de oxidação da corrida) e A3 (após processo de desoxidação e homogeneização no VOD) e a maior quantidade de inclusões na amostra A2 (após sopro de oxigênio no VOD). Após adição de titânio no Forno Panela (amostras A4 e A5), houve aumento considerável na quantidade de pequenas inclusões. Esta etapa apresentou-se como a mais crítica para alterar a condição de limpidez da corrida, visto que é realizada na etapa de refino. No entanto, com tempo de flotação maior (amostra A5), a quantidade total de inclusões diminuiu com pequeno aumento na quantidade de inclusões maiores que 2 $\mu \mathrm{m}$. A análise quantitativa na amostra A6 confirma as observações feitas no 
microscópio óptico, onde a amostra apresentou uma condição pior. Houve aumento na quantidade total de inclusões em relação à amostra A5 e também aumento considerável de inclusões $\geq 2 \mu \mathrm{m}$. Estes resultados mostram que a condição de limpidez da corrida também é modificada no lingotamento.

\subsection{Inclusões após Vazamento na Panela do Convertedor AOD para o VOD}

A tabela 6 apresenta os resultados de composição química das principais inclusões analisadas no MEV-EDS nesta etapa.

Tabela 6. Composição química das inclusões na amostra A1

\begin{tabular}{|c|c|c|c|c|c|}
\hline Composição Química & $\begin{array}{c}\text { Inclusão 1 } \\
\text { Tipo Carboneto }\end{array}$ & $\begin{array}{c}\text { Inclusão 2 } \\
\text { Tipo Oxido }\end{array}$ & $\begin{array}{c}\text { Inclusão 3 } \\
\text { Tipo Oxido }\end{array}$ & $\begin{array}{c}\text { Inclusão 4 } \\
\text { Tipo Carboneto }\end{array}$ & $\begin{array}{c}\text { Inclusão 5 } \\
\text { Tipo Óxido }\end{array}$ \\
\hline $\mathbf{C}$ & $27 \%$ & & & $36 \%$ & \\
\hline $\mathbf{C r}$ & $27 \%$ & $65 \%$ & $61 \%$ & & \\
\hline $\mathbf{N b}$ & $47 \%$ & & & $64 \%$ & \\
\hline $\mathbf{M n}$ & & $15 \%$ & $16 \%$ & & \\
\hline $\mathbf{S i}$ & & & & & $26 \%$ \\
\hline $\mathbf{S}$ & & & $23 \%$ & & $74 \%$ \\
\hline $\mathbf{O}$ & & $20 \%$ & & & \\
\hline
\end{tabular}

As inclusões 1 e 4 aparecem como sendo partículas de carbonetos de cromo e nióbio.

Nesta etapa do processo é realizado a descarburação parcial da corrida. Conforme resultado da amostra $A 1$ na tabela 1, ao final do processo no AOD é obtido alto de teor de carbono para um aço inoxidável $(0,39 \%)$. Considerando os altos teores de carbono e cromo $(11,15 \%)$ e teor de nióbio residual proveniente da sucata $(0,05 \%)$, é possível a formação destes carbonetos no resfriamento da amostra visto que o carbono apresenta grande afinidade com o cromo e nióbio.

A inclusão 2 aparece como sendo inclusão a base de cromo e manganês, do tipo $\mathrm{MnO} . \mathrm{Cr}_{2} \mathrm{O}_{3}$ (cromo-galaxita). Conforme estudos de Nolli e Mapelli (2003), $\mathrm{Cr}_{2} \mathrm{O}_{3}$ pura forma durante a oxidação e pode agir como núcleos para inclusões que precipitam durante o período de redução [3]. Embora o teor de manganês no aço seja baixo sem adições de ligas de manganês e devido a possibilidade deste elemento modificar o óxido de cromo ser baixa, o óxido duplo $\mathrm{MnO} \mathrm{Cr}_{2} \mathrm{O}_{3}$ (cromo-galaxita) pode estar presente. Esta é uma fase comum de inclusões em aços ao cromo. Ligas de ferro-cromo adicionada no processo de elaboração podem conter este óxido com inclusões ricas em manganês [4].

A inclusão 3 apresenta composição típica de um sulfeto de cromo e manganês. Conforme dados da tabela 1, ao final do processo do AOD a corrida apresenta teor de enxofre mais alto (0,0067\%). De acordo com Kiessling [4], cromo pode atuar como elemento substitucional no sistema a-MnS e vários exemplos de inclusões de sulfetos deste sistema com considerável quantidade cromo em solução foi observada pelo autor. A principal ocorrência de cromo em sulfetos aparece como sendo de sulfetos duplos do tipo $\mathrm{MnS} \mathrm{Cr}_{2} \mathrm{~S}_{3}$. A microdureza destes sulfetos é considerada maior do que o sulfeto de MnS puro [4].

A inclusão 5 apresenta-se como um óxido de silício, produto da desoxidação da corrida. Este resultado esta coerente com os estudos de Nolli e Mapelli [3] que mostraram inclusões de $\mathrm{SiO}_{2}$ pura podem se formar como produto da desoxidação no início deste processo [3]. 


\subsection{Inclusões após sopro no VOD}

A tabela 7 apresenta resultado de composição das principais inclusões observadas nesta etapa.

Tabela 7. Composição química das inclusões na amostra A2.

\begin{tabular}{|c|c|}
\hline Composição Química & $\begin{array}{c}\text { Inclusão 1 } \\
\text { Tipo Óxido }\end{array}$ \\
\hline $\mathbf{C r}$ & $50 \%$ \\
\hline $\mathbf{M n}$ & $17 \%$ \\
\hline $\mathbf{O}$ & $33 \%$ \\
\hline
\end{tabular}

Os resultados apontam para a predominância do óxido de cromo com a ocorrência do oxido de manganês. Apesar de o processo de descarburação ser realizado sob vácuo, inevitavelmente parte do cromo é oxidado. Isto é notado quando é comparado os teores de cromo nas amostras A1 (antes do sopro de oxigênio) e A2 (após sopro de oxigênio) da tabela 1. Também foi observado que parte do manganês, embora em baixo teor, também foi oxidado no processo.

Após o processo de sopro, parte do cromo e demais elementos oxidados ficam na escória e outra parte fica suspensa no banho em forma de inclusões, devido o teor considerável de cromo no aço e afinidade do oxigênio por este elemento, as principais inclusões nesta etapa são inclusões do tipo óxido de cromo.

$\mathrm{O}$ óxido de manganês esta relacionado com o manganês oxidado e com a possibilidade de ocorrência do óxido duplo $\mathrm{MnO} \cdot \mathrm{Cr}_{2} \mathrm{O}_{3}$, conforme descrito no item 3.4.

\subsection{Inclusões após Redução no VOD}

Nesta etapa começa o processo de refino do aço. Objetivo é recuperar o cromo oxidado na etapa anterior e realizar a desoxidação. A redução do cromo e a desoxidação é realizada pela adição de $\mathrm{FeSi}$.

A eficiência da recuperação do cromo pode ser medida comparando os teores de cromo na amostra A2 (após sopro) e A3 (após redução) na tabela 1. O teor de $\mathrm{Cr}_{2} \mathrm{O}_{3}$ na escória (amostra E2) na tabela 2 também serve como parâmetro de referência. $\mathrm{Cr}_{2} \mathrm{O}_{3}$ menor que 0,5 indica uma boa eficiência de recuperação do cromo oxidado na descarburação.

$\mathrm{Na}$ análise realizada no MEV, inclusões com 4 composições químicas diferentes foram encontradas dentre as principais. A tabela 8 apresenta as análises destas inclusões.

Tabela 8. Composição química das inclusões na amostra A3.

\begin{tabular}{|c|c|c|}
\hline Composição Química & $\begin{array}{c}\text { Inclusão 1 } \\
\text { Tipo Óxido }\end{array}$ & $\begin{array}{c}\text { Inclusão 2 } \\
\text { Tipo Óxido }\end{array}$ \\
\hline $\mathbf{S i}$ & $25 \%$ & $30 \%$ \\
\hline $\mathbf{C a}$ & $6 \%$ & $12 \%$ \\
\hline $\mathbf{M g}$ & $19 \%$ & \\
\hline $\mathbf{A l}$ & $6 \%$ & \\
\hline $\mathbf{O}$ & $44 \%$ & $58 \%$ \\
\hline
\end{tabular}

De uma forma geral as inclusões são silicatos de cálcio com traços de alumínio e magnésio. $\mathrm{A} \mathrm{SiO}_{2}$ pura forma quando $\mathrm{FeSi}$ é adicionado e quando a atividade do oxigênio ainda é alta. Com o passar do tempo, com a redução do potencial de 
oxigênio, inclusões de sílica pura não são mais estáveis, podendo ser modificadas pela presença de outros elementos como cálcio, magnésio e alumínio.

A tendência de reação entre $\mathrm{CaO}$ e $\mathrm{SiO}_{2}$ é muito alta, formando silicatos do tipo CaO. $\mathrm{SiO}_{2}, 3 \mathrm{CaO} .2 \mathrm{SiO}_{2}, 2 \mathrm{CaO} . \mathrm{SiO}_{2}, 3 \mathrm{CaO} . \mathrm{SiO}_{2}$ [5]. Como o teor de cálcio no aço é muito baixo, este não é capaz de reduzir a sílica para formar os silicatos. No entanto, como a linha de escória nas panelas é constituída por refratários dolomíticos, isto torna possível a formação de inclusões de magnésio e cálcio que podem modificar as inclusões de sílica. O alumínio presente na liga de FeSi pode ser oxidado, formando $\mathrm{Al}_{2} \mathrm{O}_{3}$. $\mathrm{O}$ contato da alumina com sílica pode formar óxidos complexos de sílica e alumina do tipo $3 \mathrm{Al}_{2} \mathrm{O}_{3} .2 \mathrm{SiO}_{2}$.

O fato de não se ter observado inclusões de cromo também indica que o processo foi eficiente no sentido de reduzir as inclusões de cromo observadas na etapa anterior.

\subsection{Inclusões no Forno Panela após Adição de Titânio e 5 min de Flotação}

Para evitar a perda de titânio por oxidação é extremamente importante uma boa condição de desoxidação das corridas antes da adição de titânio e também uma escória bem desoxidada com baixo teor de óxidos redutíveis. A oxidação do aço e da escória pode ser medida pelo teor de silício no aço após redução do VOD (amostra $\mathrm{A} 3$ da tabela 1) e teor de $\mathrm{Cr}_{2} \mathrm{O}_{3}$ na escória (amostra E3 da tabela 2).

Após a adição de titânio é realizada flotação com o objetivo de remover as inclusões através da escória.Mesmo após $5 \mathrm{~min}$ de flotação, a quantidade de inclusões aumentou de forma significativa em relação à etapa anterior, porém inclusões muito pequenas.

Análises químicas das principais inclusões encontradas estão apresentadas na tabela 9.

Tabela 9. Composição química das inclusões na amostra A4.

\begin{tabular}{|c|c|c|c|c|}
\hline Composição Química & $\begin{array}{c}\text { Inclusão 1 } \\
\text { Tipo Óxido }\end{array}$ & $\begin{array}{c}\text { Inclusão 2 } \\
\text { Tipo Óxido }\end{array}$ & $\begin{array}{c}\text { Inclusão 3 } \\
\text { Tipo Óxido }\end{array}$ & $\begin{array}{c}\text { Inclusão 4 } \\
\text { Tipo Óxido }\end{array}$ \\
\hline $\mathbf{T i}$ & $40 \%$ & $45 \%$ & $44 \%$ & $60 \%$ \\
\hline $\mathbf{C a}$ & $10 \%$ & $10 \%$ & $15 \%$ & \\
\hline $\mathbf{A l}$ & $3 \%$ & & $5 \%$ & \\
\hline $\mathbf{M g}$ & $10 \%$ & $8 \%$ & & \\
\hline
\end{tabular}

São inclusões de óxido de titânio com cálcio, magnésio e alumínio. No início do processo é possível observar inclusões de titânio puras. Inclusões de cálcio e magnésio podem ter originado da linha de escória conforme discutido no item 3.6, que posteriormente modificaram as inclusões de titânio. $O$ alumínio incorporado proveniente da liga de FeTi pode ter reduzido a sílica formando inclusões $\mathrm{Al}_{2} \mathrm{O}_{3}$. Este fato pode ser comprovado através do incremento de alumínio no aço após a adição de titânio, seguido do aumento de silício no aço (amostra A4).

\subsection{Inclusões no Forno Panela após Adição de Titânio e 8 min de Flotação}

A tabela 10 apresenta análises químicas das principais inclusões encontradas nesta etapa. 
Tabela 10. Composição química das inclusões na amostra A5.

\begin{tabular}{|c|c|c|c|}
\hline Composição Química & $\begin{array}{c}\text { Inclusão 1 } \\
\text { Tipo Óxido }\end{array}$ & $\begin{array}{c}\text { Inclusão 2 } \\
\text { Tipo Óxido }\end{array}$ & $\begin{array}{c}\text { Inclusão 3 } \\
\text { Tipo Óxido }\end{array}$ \\
\hline $\mathbf{T i}$ & $45 \%$ & $57 \%$ & $56 \%$ \\
\hline $\mathbf{C a}$ & $11 \%$ & $10 \%$ & $14 \%$ \\
\hline $\mathbf{A l}$ & $5 \%$ & & \\
\hline $\mathbf{M g}$ & $10 \%$ & $6 \%$ & $30 \%$ \\
\hline $\mathbf{O}$ & $29 \%$ & $27 \%$ & \\
\hline
\end{tabular}

Em termos de composição química não houve alteração significante no tipo de inclusão com aumento no tempo de flotação, permanecendo as inclusões de óxido de titânio modificadas com cálcio, magnésio e alumínio. No entanto, inclusões puras de óxido de titânio não foram observadas, indicando que com o passar o tempo, todas as inclusões foram modificadas.

A redução da quantidade inclusões a base de titânio com aumento do tempo de flotação, obtida no item 3.3, pode também ser confirmada mediante análise do óxido de titânio na escória comparado os valores de $\mathrm{TiO}_{2}$ das amostras E4 e E5 na tabela 2. Com maior tempo de flotação, houve aumento na quantidade de óxidos de titânio na escória.

\subsection{Inclusões no Distribuidor do Lingotamento Contínuo aos $20 \mathrm{~min}$ de Lingotamento}

A tabela 11 apresenta resultados de composição química das principais inclusões analisadas.

Tabela 11. Composição química das inclusões na amostra A6.

\begin{tabular}{|c|c|c|c|}
\hline Composição Química & $\begin{array}{c}\text { Inclusão 1 } \\
\text { Tipo Óxido }\end{array}$ & $\begin{array}{c}\text { Inclusão 2 } \\
\text { Tipo Óxido }\end{array}$ & $\begin{array}{c}\text { Inclusão 3 } \\
\text { Tipo Nitreto }\end{array}$ \\
\hline $\mathbf{T i}$ & $60 \%$ & $62 \%$ & $85 \%$ \\
\hline $\mathbf{C a}$ & $7 \%$ & $10 \%$ & \\
\hline $\mathbf{M g}$ & $10 \%$ & & \\
\hline $\mathbf{N}$ & & & $15 \%$ \\
\hline $\mathbf{O}$ & $23 \%$ & $28 \%$ & \\
\hline
\end{tabular}

A composição química das inclusões do tipo óxidos foi próxima aquela observada no Forno Panela, exceto pela ausência de alumínio e a presença de nitretos de titânio. Estes resultados estão coerentes com o trabalho de Wang et al. [6] em aços inoxidáveis ferríticos estabilizados. Os autores mostraram que as inclusões formadas no aço com 0,31\% de Ti são partículas de TiN e óxidos complexos de titânio [6].

Devido à afinidade do nitrogênio com titânio, pequenas partículas de nitretos de titânio precipitam, confirmando que os precipitados amarelados observados no microscópio óptico no item 3.2 são partículas pequenas de TiN.

A precipitação de nitretos de titânio ocorre em temperaturas mais baixas. No distribuidor, a temperatura do aço líquido é em torno dos $1530^{\circ} \mathrm{C}$ enquanto no Forno Panela é de $1600^{\circ} \mathrm{C}$. No trabalho realizado por Wang et al. [6], os autores definiram quea temperatura de precipitação é de $1523^{\circ} \mathrm{C}$. 


\section{CONCLUSÕES}

As análises mostraram que as inclusões são modificadas ao longo da elaboração no aço 409 de acordo com os tratamentos empregados em cada processo. Aspectos relacionados às características dos processos e origem das inclusões encontradas foram abordados.

Após AOD, inclusões do tipo carbonetos de cromo e nióbio foram encontradas assim como sulfetos de cromo e manganês do tipo $\mathrm{MnS} \mathrm{Cr}_{2} \mathrm{~S}_{3}$, além de inclusões do tipo $\mathrm{MnO} . \mathrm{Cr}_{2} \mathrm{O}_{3}$ (cromo-galaxita).

Após etapa de sopro no VOD, houve aumento significativo na quantidade de inclusões associado à oxidação de elementos no banho como cromo e manganês.

A quantidade de inclusões foi reduzida drasticamente após etapa de redução e homogeneização sob vácuo, mostrando a eficiência do processo. As principais inclusões após este processo são inclusões de sílica modificadas pelo cálcio, alumínio e magnésio, formando óxidos complexos.

Após adição de titânio no Forno Panela, a condição de limpidez foi afetada de forma significativa com aumento da quantidade total de inclusões, embora pequenas na maioria $<2 \mu \mathrm{m}$, mesmo com 5 min de flotação. Óxidos de titânio puro e óxidos de titânio com cálcio magnésio e alumínio foram encontrados como sendo as principais inclusões

O aumento do tempo de flotação não modificou de forma considerável a composição química das inclusões. Óxidos puros de titânio não foram observados, indicando que com o passar o tempo, todas as inclusões foram modificadas pelo cálcio, magnésio e alumínio. No entanto, o tempo de flotação teve efeito significativo na diminuição da quantidade de inclusões de titânio, confirmada pelo aumento deste óxido na escória.

As inclusões no distribuidor apresentaram composição química típica àquelas observadas no Forno Panela, exceto pela ausência de alumínio e a presença de nitretos de titânio. A precipitação de nitretos de titânio foi favorecida pela temperatura de processo. Esta etapa apresentou a pior condição de limpidez da corrida com aumento na quantidade total de inclusões em relação ao Forno Panela e também aumento considerável de inclusões $\geq 2 \mu \mathrm{m}$.

\section{REFERÊNCIAS}

1 Pires, J.C.S.Análise Termodinâmica e Avaliação Experimental da Formação de Inclusões em Aços de Baixo Carbono ao Longo das Etapas de Elaboração e Solidificação no Lingotamento Contínuo. Campinas: Faculdade Estadual de Campinas, 2004, 194 pp. (Tese, Doutorado em Engenharia de Materiais e Processos de Fabricação).

2 Cunha, M. N.; Coimbra, D. L.; Coelho, M. F.; Alvarenga, V. P.; Morais, J. E. A. Melhoria de qualidade superficial no aço 430 estabilizado ao nióbio através do controle de teor de alumínio. In: SEMINÁRIO DE ACIARIA, 45, 2014, Porto Alegre. Associação Brasileira de Metalurgia, Minas e Materiais (ABM), 2014.

3 Mapelli, C.; Nolli, P. Formation mechanism of non-metallic inclusions in different stainless steels grades. ISIJ International. v. 43, № 8, p. 1191-1199, 2003.

4 Kiessling, R.; Lange, N. Non-Metallic Inclusions in Steel. London: The Metals Society, 1978.

5 Payandeh. Y.; Soltanieh. M. Oxide inclusions at different steps of steel production. Journal of Iron and Steel Research, international. v. 5, p. 39-46, 2007.

6 Wang, H.; Sun, L.; Peng, B.; Jiang, M. Inclusions for ultra-pure ferritic stainless steels containing $21 \%$ chromium. Journal of Iron and Steel Research, international. v. 10, p. $70-$ 74, 2013. 